\title{
DEFORMATION AND CONSOLIDATION AROUND ENCASED STONE COLUMNS
}

\author{
by \\ Jorge Castro $\left({ }^{1}\right)(*)$ and César Sagaseta $\left({ }^{2}\right)$ \\ Group of Geotechnical Engineering \\ Department of Ground Engineering and Materials Science \\ University of Cantabria \\ Avda. de Los Castros, s/n \\ 39005 Santander, Spain \\ Tel.: +34942 201813 \\ Fax: +34 942201821 \\ e-mail: $\left({ }^{1}\right)$ castrogj@unican.es $\left({ }^{2}\right)$ sagasetac@unican.es \\ (*) Corresponding Author
}

Citation:

Castro, J., Sagaseta, C. 2011. Deformation and consolidation around encased stone columns. Geotextiles and Geomembranes 29, 268-276. DOI:

10.1016/j.geotexmem.2010.12.001 


\section{Corrigendum:}

Castro, J., Sagaseta, C. 2013. Corrigendum to "Deformation and consolidation around encased stone columns" [Geotextiles Geomembranes 29 (2011) 268-276]. Geotextiles and Geomembranes 36, 19. DOI: 10.1016/j.geotexmem.2012.10.002

The authors regret an error in Eq. (6) of the paper, which should be replaced with the following:

$$
\varepsilon_{z, u}=\frac{p_{a}}{\frac{1}{a_{r}}\left(\lambda_{c}+G_{c}+G_{s}\right)-\left(G_{c}-G_{s}\right)\left(2-3 a_{r}\right)+\frac{\left(1-a_{r}\right)^{2}}{a_{r}} \frac{J_{g}}{2 r_{c}}}
$$

The use of the constant $H$ to obtain the vertical strain was not appropriate because the term of the encasement stiffness is slightly different. However, $H$ (Eq. (4)) is still valid to get other strains and stresses in the undrained situation.

The error in Eq. (6) affects the results of the undrained situation but the differences are so small that they are not noticeable in the figures of the paper. 


\section{ABSTRACT}

A new analytical solution is presented to study soft soil improvement, both reduction of settlement and consolidation time, by means of encased stone columns. The proposed solution pretends to be a simple and useful tool for design. Therefore, only a unit cell, i.e. an end-bearing column and its surrounding soil, is modelled in axial symmetry under a rigid and constant load. Soil is assumed as elastic but plastic strains are considered in the column using the Mohr-Coulomb yield criterion and a non-associated flow rule, with a constant dilatancy angle. An elasto-plastic behaviour is also considered for the encasement by means of a limit tensile strength. The solution is presented in a closed form and is directly usable in a spreadsheet. Parametric studies of the settlement reduction, stress concentration and consolidation time show the efficiency of encasing the columns, which is mainly ruled by the encasement stiffness compared to that of the soil. Column encasement is equally useful for common area replacement ratios but columns of smaller diameters are better confined. Besides, the applied load should be limited to prevent the encasement from reaching its tensile strength. A simplified formulation of the solution is developed assuming drained condition. The results agree well with numerical analyses.

KEYWORDS: Encased stone columns, elasto-plastic, analytical solution, settlement reduction, consolidation. 


\section{NOTATION}

$a_{r}$

$c_{v}$

$c_{u}$

$k$

$p_{a}$

$r_{l}, r_{c}$

$s$

$S_{z 0}$

A

E

$E_{m}$

G

$J_{g}$

$K_{0}$

$K$

$L$

$N$

$S C F$

$T_{g}$

$T_{g, \max }$
Area replacement ratio: $a_{r}=A_{c} / A_{l}$

Coefficient of consolidation

Undrained shear strength

Coefficient of permeability

Applied vertical unit load

Radius of the unit cell, of the column

Displacements

Settlement without columns

Cross-section

Young's modulus

Oedometric (constrained) modulus: $E_{m}=[E(1-v)] /[(1+v)(1-2 v)]$

Shear modulus: $G=E /[2(1+v)]$

Tensile stiffness of the encasement

Coefficient of at rest lateral pressure

Coefficient of active earth pressure

Column length

Column spacing ratio: $N=r_{l} / r_{c}$

Stress concentration factor: $S C F=\sigma_{z c} / \sigma_{z s}$

Tensile stress of the encasement

Maximum tensile strength of the encasement 


$\begin{array}{ll}\beta & \text { Settlement reduction factor: } \beta=s_{z} / s_{z 0} \\ \phi & \text { Friction angle } \\ \gamma & \text { Unit weight } \\ \lambda & \text { Lamé's constant: } \lambda=2 G v /(1-2 v)=E_{m}-2 G \\ v & \text { Poisson's ratio } \\ \psi & \text { Dilatancy angle }\end{array}$

Subscripts/superscripts:

$\begin{array}{ll}c, g, s, l & \text { column, encasement, soil, elementary cell } \\ e, p & \text { elastic, plastic } \\ i, u, f, y & \text { initial (previous), undrained, final, at yielding } \\ r, z, \theta & \text { cylindrical coordinates }\end{array}$

(upper bar): average value along the radius 


\section{INTRODUCTION}

Stone columns are one of the most common improvement techniques for foundation of embankments or structures on soft soils. They are vertical boreholes in the ground, filled upwards with gravel compacted by means of a vibrator. Unlike other improvement techniques, stone columns are considered not to affect significantly the properties of the surrounding ground. The main effects usually considered with respect to the untreated ground conditions are: improvement of bearing capacity, reduction of total and differential settlements, acceleration of consolidation, improvement of the stability of embankments and natural slopes, and reduction of liquefaction potential.

Vertical capacity of stone columns is related to the lateral confinement provided by the surrounding soil. Very soft soils may not provide enough lateral support for a proper performance of a stone column treatment. The undrained shear strength of the surrounding soil is generally used as the criterion to decide the feasibility of the treatment, with lower bound in the range 5-15 kPa (Wehr, 2006). In recent years, geotextile encasement is one of the alternatives that have been successfully used to extend the use of stone columns to those extremely soft soils. Apart from the lateral support, geotextile encasement acts as a filter between clay and gravel; this ensures the effective drainage and avoids contamination of the gravel with fines. Lately, other geosynthetics, such as geogrids, are also used for column encasement (Sharma et al., 2004; Gniel and Bouazza, 2009) because of its high tensile stiffness, yet they cannot avoid gravel contamination. 
Besides experimental work, research on encased stone columns is mostly done using numerical methods (e.g. Murugesan and Rajagopal, 2006; Malarvizhi and Ilamparuthi, 2007) and very few analytical solutions are available (Raithel and Kempfert, 2000). This paper presents a new analytical solution to study the settlement reduction and the acceleration of consolidation caused by encased stone columns. The proposed solution is an extension of another analytical solution recently developed by the authors for stone columns (Castro and Sagaseta, 2009). The solution assumes linear elastic behaviour of soil and linear elastic-perfectly plastic behaviour of encasement and column. Furthermore, the proper loading history is considered (undrained loading and consolidation analysis), and equilibrium and compatibility conditions, both in vertical and radial directions, are fulfilled. So, many of the limitations of the existing analytical solutions (Raithel and Kempfert, 2000) are overcome.

The analytical solution gives a quantitative assessment of the improvement introduced by the column encasement and the influence of its stiffness on the system performance. The axial tensile stress of the encasement is also evaluated. Finally, the analytical solution is compared with numerical analyses.

\section{PROPOSED SOLUTION}

\section{Model}

Column encasement may be very useful under concentrated loads (Murugesan and Rajagopal, 2010) but the presented analytical solution is based on a "unit cell" model (Figure 1) and is, therefore, limited to distributed uniform loads. Because of the symmetry, only one column and its surrounding soil are studied in axial symmetry. 
Furthermore, the column is assumed to be fully penetrating in the soft soil and the applied load is considered as rigid, i.e. uniform settlement. The area of soft soil, $A_{l}$, that is improved by each column, $A_{c}$, is generally expressed by the area replacement ratio, $a_{r}=A_{c} / A_{l}$, but sometimes is also defined in terms of the relation between diameters or radii, $N=r_{l} / r_{c}=\sqrt{1 / a_{r}}$.

The solution is developed for a horizontal slice at a depth $z$ of the unit cell, and consequently, shear stresses between slices at different depths are not considered. The overall behaviour of the whole unit cell is obtained by means of integration of the solution at the different depths.

\section{Consolidation}

Consolidation around encased stone columns is a fully coupled problem. However, a reasonably accurate simple solution can be obtained using the average value of the excess pore pressure along the radius, $\bar{u}$. The details of this kind of approach can be found in Castro and Sagaseta (2009). Only one instantaneous load step is considered and remoulding effects during installation that may alter the soil permeability are neglected. A further assumption is the infinite permeability of the column (drain), which is doubtful for conventional stone columns but is reasonable if the columns are coated with a geotextile. In this way, consolidation around encased stone columns is studied using any conventional solution for radial consolidation (e.g. Barron, 1948) and a modified coefficient of consolidation that accounts for the influence of column and encasement. 


\section{Encasement}

Although stone columns are commonly encased using geosynthetics, or more precisely geotextiles or geogrids, the term encasement is preferred here for the sake of generality. It is modelled as a cylindrical shell of negligible thickness around the column. Encasement behaviour is supposed to be linear elastic-perfectly plastic and characterized by a tensile stiffness, $J_{g}$, and a maximum tensile strength, $T_{g, \max }$ (Figure 1 ). During column installation, the encasement is pre-stressed to an initial tensile stress, $T_{g, i}$.

Vertical interaction of the encasement with the soil and column through friction is considered to be rather small and, therefore, is disregarded. So, the encasement acts only in radial direction. Its equilibrium and compatibility conditions (Figure 2) are those of a thin tube under internal, $\sigma_{r c}$, and external pressure, $\sigma_{r s}$.

$$
\begin{aligned}
& \sigma_{r c}=\frac{T_{g}}{r_{c}}+\sigma_{r s} \\
& T_{g}=J_{g} \frac{s_{r}}{r_{c}}
\end{aligned}
$$

where $s_{r}$ is the radial displacement of the interface.

Combining these two equations, the radial equilibrium between soil and column at their interface depends on the encasement properties (stiffness and radius) and its radial expansion.

$$
\sigma_{r c}=\frac{J_{g} s_{r}}{r_{c}^{2}}+\sigma_{r s}
$$




\section{Elastic solution}

In a first step, elastic behaviour is assumed for the soil, the encasement and the column. As previously mentioned, only a horizontal slice at a depth $z$ of the unit cell is analysed (Figure 3). The column is a vertical solid cylinder subjected to a vertical uniform pressure $\sigma_{z c}$ and a radial pressure $\sigma_{r c}$ at its lateral wall. The soil is a cylinder with a central cylindrical cavity, subjected to a vertical uniform effective pressure $\sigma_{z s}^{\prime}$, a radial pressure $\sigma_{r s}$ at the cavity wall (soil/encasement interface) and an excess pore pressure $\bar{u}$. The encasement is a cylinder shell that relates the radial stresses of soil and column at their interface, as explained in the previous section. These five pressures determine the stresses and strains at any point of the soil and the column, and the tensile stress of the encasement.

The conditions of vertical equilibrium and compatibility and radial equilibrium (Eq. 3) and compatibility of deformation at the encasement must be imposed. These four equations allow to express the above four vertical or radial pressures in terms of the pore pressure $\bar{u}$ and the applied vertical pressure $p_{a}$ only.

The development of the solution is analogous to that without encasement (Castro and Sagaseta, 2009) and most importantly, the solution is exactly the same but adjusting the constants $H$ and $F$ to account for the encasement.

$$
H=\frac{1}{a_{r}}\left(\lambda_{c}+G_{c}+G_{s}\right)-\left(G_{c}-G_{s}\right)+\frac{1-a_{r}}{a_{r}} \frac{J_{g}}{2 r_{c}}
$$




$$
F=\frac{\left(1-a_{r}\right)\left(\lambda_{c}-\lambda_{s}\right)}{2\left[a_{r}\left(\lambda_{s}-\lambda_{c}+G_{s}-G_{c}\right)+\lambda_{c}+G_{c}+G_{s}+\left(1-a_{r}\right) \frac{J_{g}}{2 r_{c}}\right]}
$$

$H$ and $F$ are constants of the solution for the undrained and final elastic states, respectively. For instance, they relate the applied load to the vertical strain as follows:

$$
\begin{aligned}
& \varepsilon_{z, u}=\frac{p_{a}}{H-\left(1-3 a_{r}\right)\left(G_{c}-G_{s}\right)} \\
& \varepsilon_{z, f}^{e}=\frac{p_{a}}{\left(\lambda_{c}+2 G_{c}\right) a_{r}+\left(\lambda_{s}+2 G_{s}\right)\left(1-a_{r}\right)-2 a_{r}\left(\lambda_{c}-\lambda_{s}\right) F}
\end{aligned}
$$

Both constants, $H$ and $F$, have now a new term that accounts for the encasement (Eq. (4) and (5)). As expected, encasing the column is more effective when the encasement stiffness is higher and the column diameter is lower. Eq. (4) and (5) enable a quantitative assessment of the encasement influence and, for usual soil and column properties, the improvement provided by the encasement is really small. The encasement starts to be really useful only when the soil does not provide enough lateral support and the column yields. The small influence of the encasement in the elastic case is shown up by the small increment of its tensile stress.

$$
\Delta T_{g}^{e}=J_{g} F\left(\varepsilon_{z}-\frac{\bar{u}}{\lambda_{c}-\lambda_{s}}\right)
$$

The modified coefficient of consolidation for the elastic case is the same as that without encasement but changing $H$ consistently (Eq. 4). The complete elastic solution is not detailed here to avoid repetition with Castro and Sagaseta (2009) and Balaam and Booker (1981). 


\section{Plastic deformation of the column}

Since the encasement is useful only after column yielding, the next step is to include an elastic-perfectly plastic behaviour of the column. Plastic strains in the column can be adequately modelled with the Mohr-Coulomb yield criterion and a non-associated flow

rule, with a constant dilatancy angle $\left(\psi_{c} \neq \phi_{c}\right)$. The increments of elastic strains in the column during plastic deformation are neglected to keep the solution as simple as possible. Similarly to the elastic case, the solution and its development are again analogous to those without encasement (Castro and Sagaseta, 2009). The only difference is in the constant $J$, whose value is now

$$
J=\lambda_{s}+\frac{G_{s}+a_{r}\left(G_{s}+\lambda_{s}\right)}{\left(1-a_{r}\right) K_{\psi c}}+\frac{J_{g}}{2 r_{c} K_{\psi c}}
$$

where $K_{\psi_{c}}=\frac{1-\sin \psi_{c}}{1+\sin \psi_{c}}$

Similarly to $H$ and $F$ for the undrained and final elastic states, $J$ is a constant of the solution for the plastic increment and relates, for example, the excess pore pressure increment to the vertical strain increment:

$$
\Delta \varepsilon_{z}^{p}=\frac{\left(1-a_{r}+\frac{a_{r}}{k_{a c}}\right) \overline{\Delta u}}{\left(\lambda_{s}+2 G_{s}\right)\left(1-a_{r}\right)+\frac{a_{r} \lambda_{s}}{K_{\psi c}}+\frac{a_{r} J}{K_{a c}}}
$$

The lateral confinement provided by the encasement is now considerable and its relevance depends on the ratio between the relative stiffness of the encasement and the 
soil. As a result, the increment of the tensile stress of the encasement is also significant:

$$
\Delta T_{g}^{p}=\frac{J_{g}}{2 K_{\psi_{c}}} \Delta \varepsilon_{z}^{p}
$$

In this elastic-plastic analysis, the initial stresses existing before load application must be included and as they can in general vary with depth, the analysis depends on the depth $z$. The time of yielding, the modified coefficient of consolidation, the solution of the plastic increment and its integration for the whole column are not repeated here because they are the same as those without encasement (Castro and Sagaseta, 2009) but changing the value of $J$ (Eq. 9) consistently.

\section{Tensile strength of the encasement}

The considerable increment of the tensile stress of the encasement when the column yields (Eq. 11) may cause the encasement to reach its maximum tensile strength, $T_{g, \max }$. Therefore, the condition of encasement yielding must be imposed.

$$
T_{g, \max }-T_{g, i}-\Delta T_{g}^{y}=\Delta T_{g, \text { max }}^{p}=\frac{J_{g}}{2 K_{\psi c}} \Delta \varepsilon_{z}^{p y}
$$

$\Delta T_{g}^{y}$ is the tensile stress increment at column yielding (Eq. 8). The superscript " $p y$ " refers to plastic column and encasement yielding. The pore pressure at the moment of encasement yielding, $\overline{u_{p y}}$, is related to $\Delta \varepsilon_{z}^{p y}$ (Eq. 10). 


$$
\Delta \varepsilon_{z}^{p y}=\frac{\left(1-a_{r}+\frac{a_{r}}{K_{a c}}\right)\left(\overline{u_{p y}}-\overline{u_{y}}\right)}{\left(\lambda_{s}+2 G_{s}\right)\left(1-a_{r}\right)+\frac{a_{r} \lambda_{s}}{K_{\psi c}}+\frac{a_{r} J}{K_{a c}}}
$$

where $J$ is defined by Eq. (9).

After encasement yielding, the solution is the same as that without encasement and it can be found in Castro and Sagaseta (2009). As a remark, now $J$ does not include the influence of the encasement, because it expands at constant hoop stress.

\section{DRAINED SOLUTION}

The presented solution considers an undrained loading followed by a consolidation process. However, consolidation around stone columns, especially if the columns are coated with a geotextile, may be nearly as fast as the loading pace, which means that for those cases drained condition is a more reasonable assumption. In any case, depending on the soil permeability and the loading pace, the real behaviour is between drained condition and an undrained loading followed by consolidation. These two different assumptions or limit cases have already been used for conventional stone columns. Pulko and Majes (2005) developed a drained solution while the authors considered the consolidation process (Castro and Sagaseta, 2009). Both solutions are slightly different when the column yields, because it follows different stress paths.

In this section, the solution is developed for drained condition, obtaining a simplified formulation for the settlement reduction factor and the tensile stress of the encasement. 
Balaam and Booker (1981) proposed the drained solution for conventional stone columns when soil and column are elastic. The drained solution for encased stone columns is the same but changing $F$ accordingly (Eq. 5). So, for example, the settlement reduction factor for this elastic case, $\beta^{e}$, is

$$
\beta^{e}=\frac{E_{m s}}{E_{m l}^{e}}
$$

where $E_{m l}^{e}$ is a kind of average oedometric modulus of the unit cell.

$$
E_{m l}^{e}=\left(1-a_{r}\right) E_{m s}+a_{r} E_{m c}-2 a_{r}\left(\lambda_{c}-\lambda_{s}\right) F
$$

The first and second terms are the weighted values of the soil and column moduli respectively and the third term is the influence of the radial displacement of the soil/column interface where the encasement is placed.

Assuming an initial geostatic stress state and neglecting the influence of column installation, the initial stresses are

$$
\begin{aligned}
& \sigma_{z s, i}=\gamma_{s}^{\prime} z \\
& \sigma_{z c, i}=\gamma_{c}^{\prime} z \\
& \sigma_{r s, i}^{\prime}=\sigma_{r c, i}=K_{0 s} \sigma_{z s, i}^{\prime} \\
& u_{i}=0
\end{aligned}
$$

Now, column yielding at a specific depth, $z$, does not depend on the time and is controlled only by the applied load, $p_{a}^{y}$. 


$$
\begin{aligned}
& p_{a}^{y}=Y z \\
& Y=\frac{E_{m l}^{e}\left(K_{0 s} \gamma_{s}^{\prime}-K_{a c} \gamma_{c}^{\prime}\right)}{2 G_{c}\left(K_{a c}+F\right)-\lambda_{c}(1-2 F)\left(1-K_{a c}\right)}
\end{aligned}
$$

The drained solution when the column is at its active limit state for a plastic increment $p_{a}^{p}=p_{a}-p_{a}^{y}$, is detailed in Table 1 , and in particular, the settlement reduction factor for a plastic column is

$$
\beta^{p}=\frac{E_{m s}}{E_{m l}^{p}}
$$

where $E_{m l}^{p}$ is again a kind of average modulus of the unit cell as (15) but for a plastic column.

$$
E_{m l}^{p}=\left(1-a_{r}\right) E_{m s}+a_{r} \frac{\lambda_{s}}{K_{\psi c}}+\frac{J a_{r}}{K_{a c}}
$$

Now, the first term is the weighted value of the oedometric modulus of the soil, the second one accounts for the plastic strains of the column (dilatancy) and the third one is the influence of the radial interaction between soil, encasement and column.

If for the sake of simplicity the encasement is assumed elastic, the average settlement reduction factor depends on the applied load that cause the yielding of the column, $p_{a}^{y}$.

$$
\beta=\beta^{e} \frac{p_{a}^{y}}{p_{a}}+\beta^{p}\left(1-\frac{p_{a}^{y}}{p_{a}}\right)
$$


$p_{a}^{y}$ depends on the depth, $z$, and so does the reduction factor, $\beta$. As encased stone columns are useful in very soft soils, whose properties generally vary with depth, it is common to split the problem in different slices. However, if the soil properties are supposed constant with depth, Eq. (20) may be integrated for the whole column of height, $L$. Column yielding starts at the surface, where the initial stresses are null, and progresses downwards as the applied load increases. Then, for an applied load, the column yields until a depth $z^{y}=p_{a} / Y$. The integration is different if only the upper part of the column is at its active limit state $\left(z^{y} \leq L\right)$ or if the whole column has yielded $\left(z^{y} \geq L\right)$. The solution for the later case is equivalent to applying Eq. (20) to the mean depth of the column $(z=L / 2)$.

$$
\begin{aligned}
& \beta=\beta^{e}\left(1-\frac{p_{a}}{2 L Y}\right)+\beta^{p} \frac{p_{a}}{2 L Y} \quad ; \quad z^{y} \leq L \\
& \beta=\beta^{e} \frac{L Y}{2 p_{a}}+\beta^{p}\left(1-\frac{L Y}{2 p_{a}}\right) \quad ; \quad z^{y} \geq L
\end{aligned}
$$

If no encasement is considered in the presented drained solution $\left(J_{g}=0\right)$, it perfectly agrees with that of Pulko and Majes (2005) for conventional stone columns.

Another interesting result of the drained solution is a simplified expression for the tensile stress of the encasement at a depth, $z$.

$$
T_{g}=J_{g}\left[\frac{F}{E_{m l}^{e}} p_{a}^{y}+\frac{1}{2 K_{\psi c} E_{m l}^{p}} p_{a}^{p}\right]
$$




\section{PARAMETRIC STUDY AND NUMERICAL ANALYSES}

\section{Numerical model}

Coupled numerical analyses of the unit cell (Figure 1) were performed using the finite element code Plaxis v8.6 (Brinkgreve, 2007). For comparison purposes, the same boundary conditions and material properties of the analytical solution were chosen for the numerical models. Therefore, a rigid plate was set on top of the unit cell, the soil was modelled as elastic and the encasement and the column as elastic-perfectly plastic.

A common range of geometries and material properties were modelled for parametric studies and comparisons with the presented analytical solution. The results of the numerical simulations reveal the accuracy of the analytical solution and the influence of its hypotheses, such as neglecting the shear stresses and using an average pore water pressure along the radius.

\section{Consolidation}

The consolidation process around an encased stone column is studied using any conventional solution for radial consolidation (e.g. Barron, 1948) and a modified consolidation coefficient that accounts for the influence of column and encasement. When the column is elastic, the encasement influence is small and the modified coefficient of consolidation, $c_{v r}^{z r e}$, is nearly the same as that without encasement (2-3 times the basic one for normal geometries and soil and column properties). By contrast, the modified coefficient of consolidation for a plastic column, $c_{v r}^{z r p}$, is clearly influenced 
by the tensile stiffness of the encasement (Figure 4). If there is no encasement (stone

column, $J_{g}=0$ ) or the encasement has reached its tensile strength, $c_{v r}^{z r p}$ is lower (0.80.9 times) than the basic one, while for usual tensile stiffnesses of the encasement, $c_{v r}^{z r p}$ is slightly higher (1-1.2 times) than the basic one.

The accuracy of the proposed solution in modelling the consolidation process is verified by numerical results in Figure 5, which shows settlement development with time. However, as it happens for the stone column solution (Castro and Sagaseta, 2009), the agreement for low degrees of consolidation $(<30 \%)$ is not very good due to inherent assumptions of Barron's solution. The small differences in the final values of the settlement will be analysed in its own section.

\section{Stress concentration}

The ratio between the vertical stress on the column and the soil is usually called stress concentration factor $\left(S C F=\sigma_{z c} / \sigma_{z s}\right)$ and gives an idea of the part of the applied load that soil transfers to the column. Figure 6 shows its variation with time. The vertical stresses on the soil and the column may vary with the radius, and therefore, their averaged values are used to calculate the $S C F$. Again, the influence of the encasement stiffness is only noticeable for a plastic column. In that case, the lateral confinement provided by the encasement allows the column to support a higher load. The distribution of the applied load between soil and column and how it is influenced by the tensile stress of the encasement are plotted in Figure 7. The stiffer the encasement is, the higher tensile stress it supports and the more lateral confinement it provides to the 
column. The tensile stress of the encasement increases notably only after column yielding.

That increase of the tensile stress may cause the encasement to reach its tensile strength and then, it no longer helps the column to support any more vertical load (Figure 8). The numerical analyses show up how well the analytical solution captures the influence of the encasement stiffness and its tensile strength. The tensile stress of the encasement increases with time until it reaches its maximum value (Figure 9). Now, a direct comparison with the numerical analyses at a specific depth is not possible because in the numerical model, as column yields, shear bands develop in the column causing the tensile stress of the encasement to fluctuate (Figure 10). However, the agreement between the numerical and the analytical results is very good but for those fluctuations of the numerical values.

\section{Settlement reduction}

The settlement reduction factor, defined as the ratio between the final settlement with and without improvement, $\beta=s_{z} / s_{z 0}$, is used in practice to evaluate the efficiency of the improvement method. The settlement reduction decreases with the applied load, $p_{a}$, from an elastic value, $\beta^{e}$, and approaches a plastic one, $\beta^{p}$, at the same rate as plastic strains develop in the column (Figure 11). The applied load is normalised by the initial vertical stress because column yielding depends on that factor, $p_{a} /\left(L \gamma_{s}^{\prime}\right)$. Figure 11 (a) illustrates the effectiveness of encasing the columns if the tensile stiffness of the encasement is high enough compared to that of the soil $\left(J_{g} /\left(r_{c} E_{s}\right)>1\right)$. So, encasing stone columns is recommended in very soft soils for moderate loads and using a stiff 
material for the encasement. If the applied load is high, the tensile stress of the encasement reaches its maximum value, $T_{g \text {,max }}$, and its effectiveness is severely reduced (Figure $11(b))$.

On the other hand, the settlement reduction introduced by the encasement is nearly the same for different area replacement ratios (Figure 12), which means that column encasement is equally useful for different area replacement ratios, yet columns of smaller diameters are better confined. In Figure 11 and Figure 12, the numerical results validate the accuracy of the analytical solution, but the agreement gets slightly worse as the tensile stiffness of the encasement increases. Hence, the only assumption that has a slightly noticeable effect in the results is neglecting the elastic strains in the column during its plastic deformation. However, that assumption is necessary to get a manageable solution.

The influence of the geotextile stiffness on the settlement reduction factor has been measured in the field (Kempfert, 2003). Although it is not possible to make a detailed comparison because of the lack of information of the different field sites, the values measured in the field of the settlement reduction factor and their variation with the geotextile stiffness are in good agreement with the proposed analytical solution (Figure 13). For a typical soft soil stiffness $\left(E_{s}=1 \mathrm{MPa}\right)$ and a column radius of $r_{c}=0.5 \mathrm{~m}$, factors of $J_{g} /\left(r_{c} E_{s}\right)=2-5$ imply a geotextile stiffness in the range $1-2.5 \mathrm{MN} / \mathrm{m}$. 


\section{Drained solution}

Along with the consolidation analysis, a drained solution has been also developed. Since the stress paths followed by the column in both analyses are not the same, different results are expected. To evaluate those differences, the settlement reduction factor is compared in Figure 14.

For further comparison, the settlement reduction factor was numerically calculated assuming drained condition. The differences between a drained and a consolidation analysis using finite elements are very small and are only noticeable for low loads when the whole column has not yielded yet. By contrast, the simplified drained formulation of the proposed solution differs visibly from the consolidation approach. The differences are greater for higher encasement stiffnesses. As it was mentioned in the previous section, the analytical solution predicts slightly lower settlements than the numerical analyses because it disregards the elastic strains in the column during plastic deformation. That phenomenon is clearer in a drained approach because the column yields earlier than it does if undrained loading and consolidation are modelled. Nevertheless, the drained solution is still very useful for a quick rough estimate of the settlement reduction factor (Eq. 21). 


\section{CONCLUSIONS}

A new analytical solution has been developed to study the deformation and consolidation around encased stone columns. The solution considers column and encasement yielding. The governing parameters are identified and their influence on the settlement, stress concentration and consolidation process is evaluated. The solution is presented in a closed form and is directly usable in a spread sheet.

Column encasement has a negligible effect for an elastic column and starts to be useful only after column yielding. The effectiveness of the encasement is directly related to its

stiffness through the factor $J_{g} /\left(r_{c} E_{s}\right)$. Therefore, encasing stone columns is recommended in soft soils using stiff encasements and under moderate loads because for high applied loads, the encasement reaches its tensile strength and does not provide any further improvement. The settlement reduction provided by the encasement does not depend on the area replacement ratio.

A simplified formulation of the proposed solution is obtained assuming drained condition.

Comparisons of the proposed solution with numerical analyses show a good agreement, which confirms the validity of the solution and its hypotheses. So, the proposed solution is a simple and accurate tool for the design of encased stone columns. 


\section{ACKNOWLEDGEMENTS}

The work presented is part of a research project on "An integrated calculation procedure for stone columns, considering the influence of the method of installation", for the Spanish Ministry of Science and Innovation (Ref.: BIA2009-13602).

\section{REFERENCES}

Balaam, N.P., Booker, J.R., 1981. Analysis of Rigid Rafts supported by Granular Piles. International Journal for Numerical and Analytical Methods in Geomechanics 5, 379-403.

Barron, R.A., 1948. Consolidation of fine-grained soils by drain wells. Transactions ASCE 113, 718-742.

Brinkgreve, R.B.J., 2007. Plaxis finite element code for soil and rock analysis, 2D, version 8. Balkema, Rotterdam.

Castro, J., Sagaseta, C., 2009. Consolidation around stone columns. Influence of column deformation. International Journal for Numerical and Analytical Methods in Geomechanics 33 (7), 851-877.

Gniel, J., Bouazza, A., 2009. Improvement of soft soils using geogrid encased stone columns. Geotextiles and Geomembranes 27 (3), 167-175.

Kempfert, H.-G., 2003. Ground improvement methods with special emphasis on column-type techniques. In: Proceedings of the International Workshop on Geotechnics of Soft Soils-Theory and Practice, SCMEP, Noordwijkerhout, The 
Netherlands, pp. 101-112.

Malarvizhi S.N., Ilamparuthi, K., 2007. Comparative study on the behaviour of encased stone column and conventional stone column. Soils and Foundations 47 (5), 873885.

Murugesan, S., Rajagopal, K., 2006. Geosynthetic-encased stone columns: Numerical evaluation. Geotextiles and Geomembranes 24 (6), 349-358.

Murugesan, S., Rajagopal, K., 2010. Studies on the Behavior of Single and Group of Geosynthetic Encased Stone Columns. Journal of Geotechnical and Geoenvironmental Engineering 136 (1), 129-139.

Pulko, B., Majes, B., 2005. Simple and accurate prediction of settlements of stone column reinforced soil. In: Proceedings of the 16th International Conference on Soil Mechanics and Geotechnical Engineering, Osaka, Japan, vol. 3, pp. 14011404.

Raithel, M., Kempfert, H.G., 2000. Calculation models for dam foundations with geotextile coated sand columns. In: Proceedings of the International Conference on Geotechnical \& Geological Engineering, GeoEngg—2000, Melbourne.

Sharma, S.R., Phanikumar, B.R., Nagendra, G., 2004. Compressive load response of granular piles reinforced with geogrids. Canadian Geotechnical Journal 41 (1), $187-192$.

Wehr, J., 2006. The undrained cohesion of the soil as criterion for the column installation with a depth vibrator. In: Proceedings of the International Symposium on vibratory pile driving and deep soil vibratory compaction, TRANSVIB 2006, Paris. 


\section{FIGURE CAPTIONS}

Figure 1. Unit cell.

Figure 2. Equilibrium and compatibility conditions of the encasement.

Figure 3. Equilibrium and compatibility conditions between soil and column.

Figure 4. Modified coefficient of consolidation. Plastic column. Influence of the encasement stiffness.

Figure 5. Time-settlement curves for common encasement stiffnesses.

Figure 6. Stress concentration factor through time. Influence of the encasement stiffness.

Figure 7. Time-dependent stress transfer.

Figure 8. Stress concentration factor through time. Plastic column. Influence of the tensile strength of the encasement.

Figure 9. Tensile stress of the encasement. Plastic column. Influence of the tensile strength of the encasement.

Figure 10. Comparison of the tensile stress of the encasement with numerical calculations.

Figure 11. Settlement reduction factor, $\beta$, with the applied load.

Figure 12. Settlement reduction factor, $\beta$. Influence of the encasement stiffness for different area replacement ratios.

Figure 13. Settlement reduction factor, $\beta$. Comparison with field measurements.

Figure 14. Comparison of drained and consolidation analyses. 


\section{TABLE CAPTIONS}

Table 1. Plastic increments of strains and stresses from the moment of column yielding for an increment of the applied load, $p_{a}^{p}$. Drained analysis. 

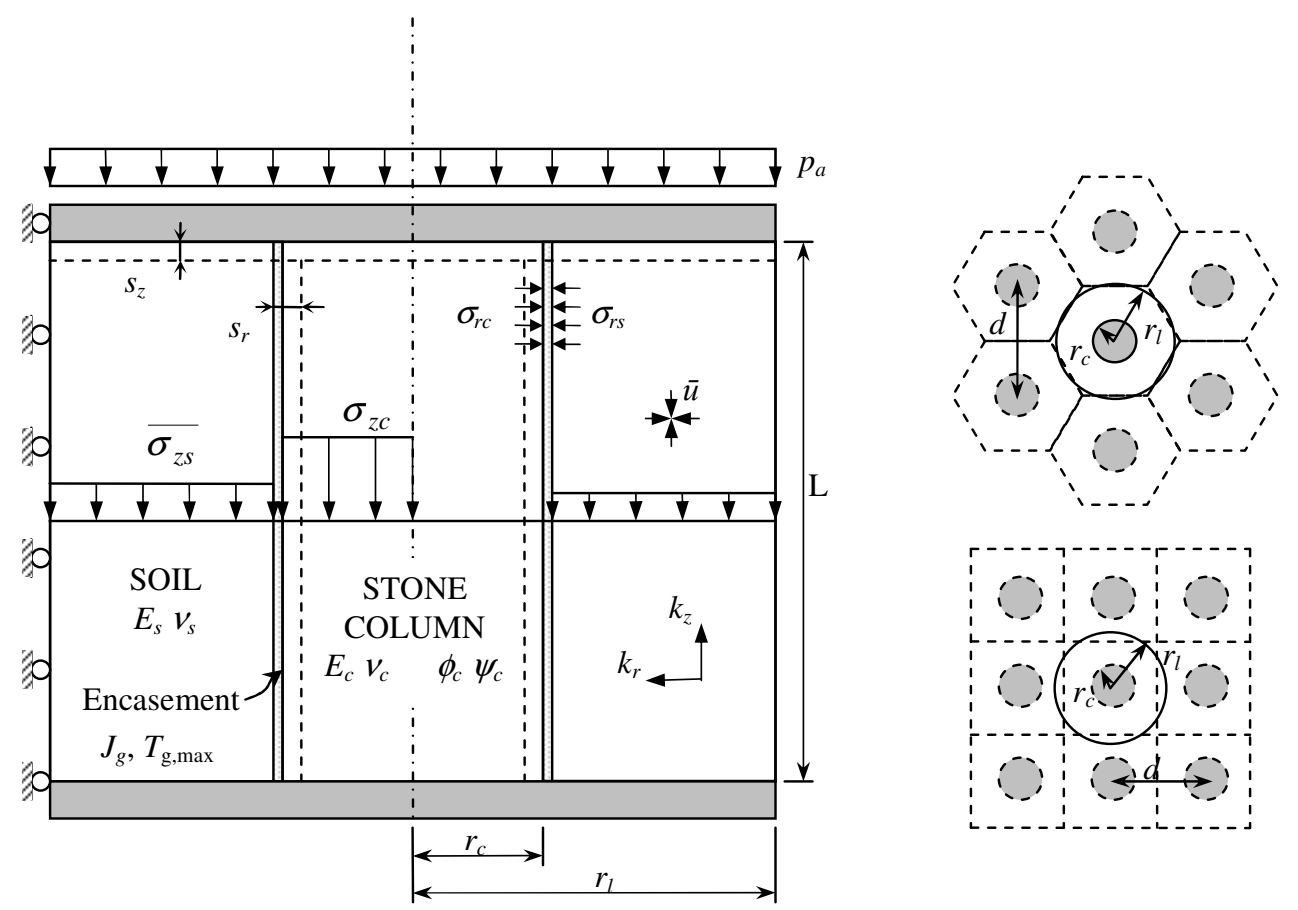

Figure 1. Unit cell. 


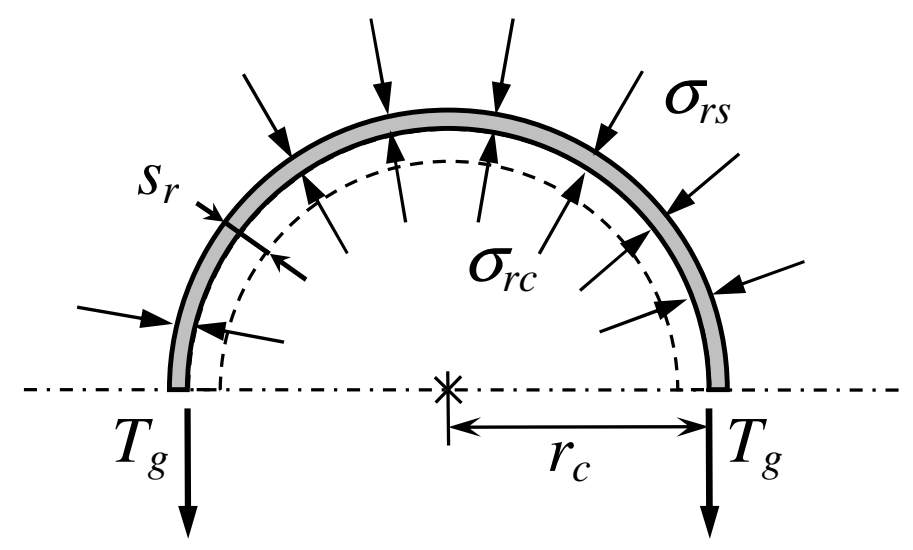

Figure 2. Equilibrium and compatibility conditions of the encasement. 


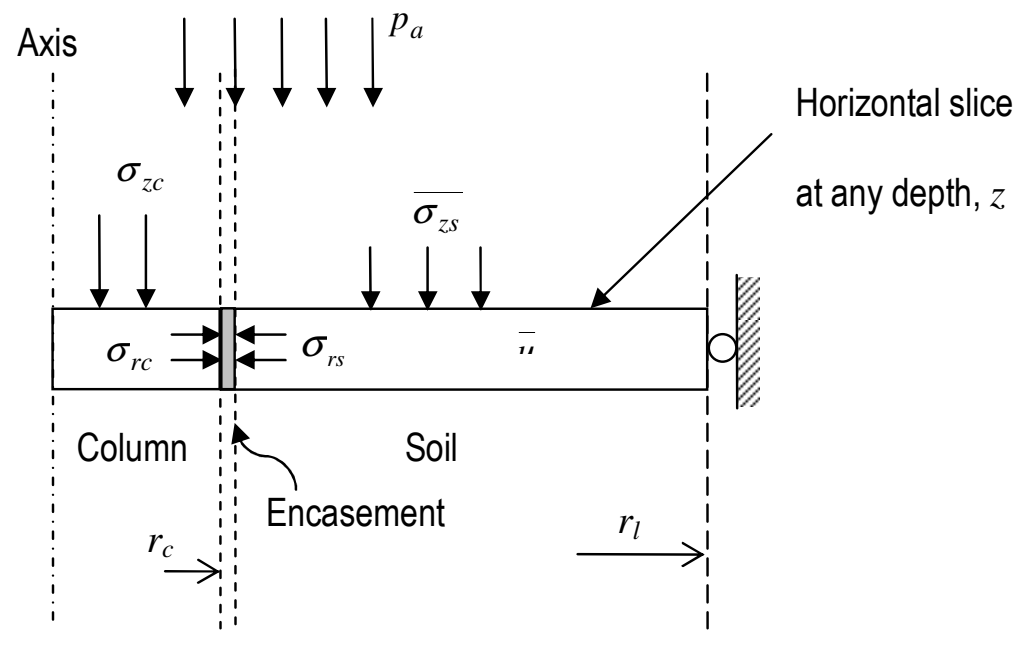

Figure 3. Equilibrium and compatibility conditions between soil and column. 


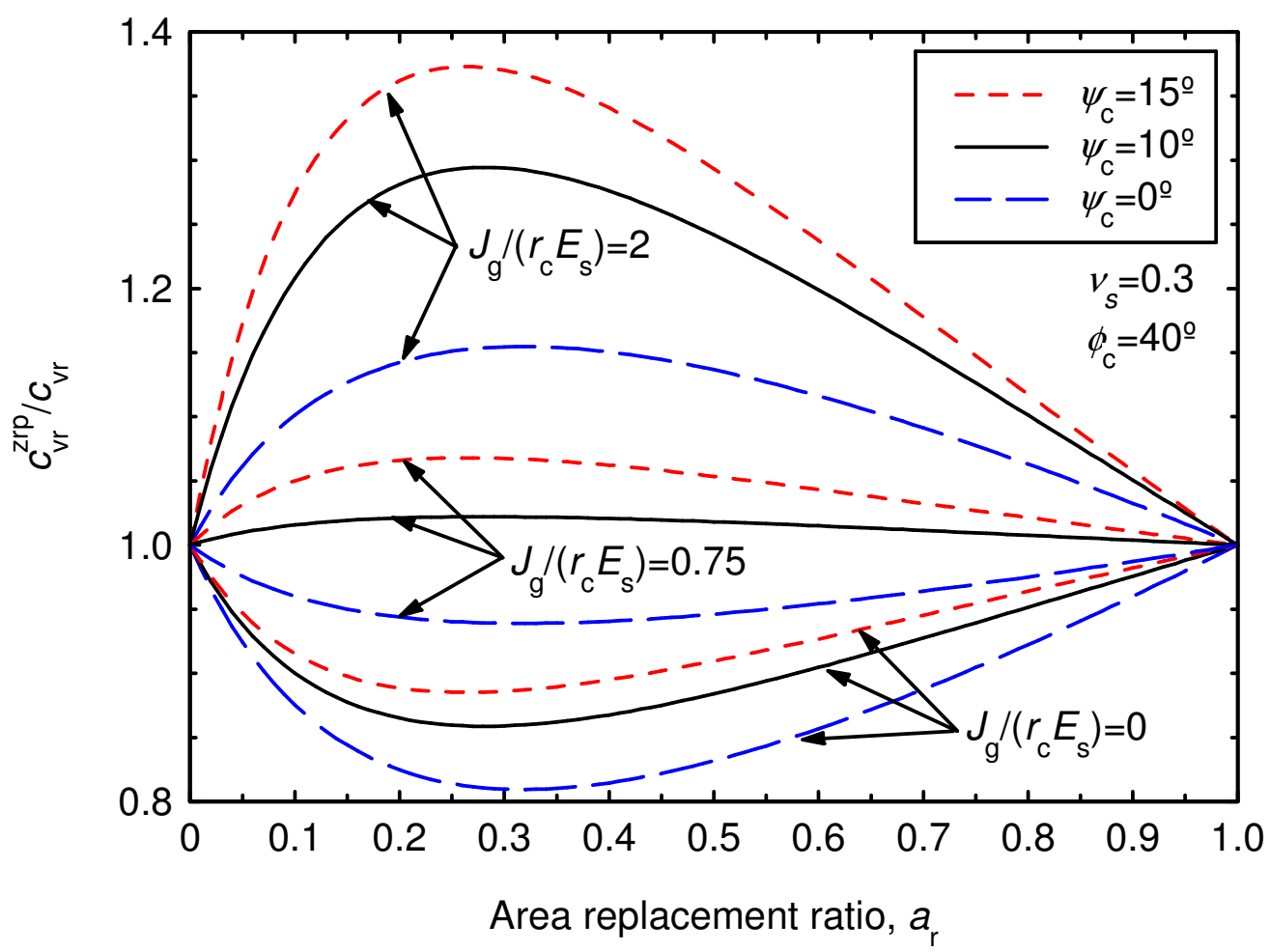

Figure 4. Modified coefficient of consolidation. Plastic column. Influence of the encasement stiffness. 


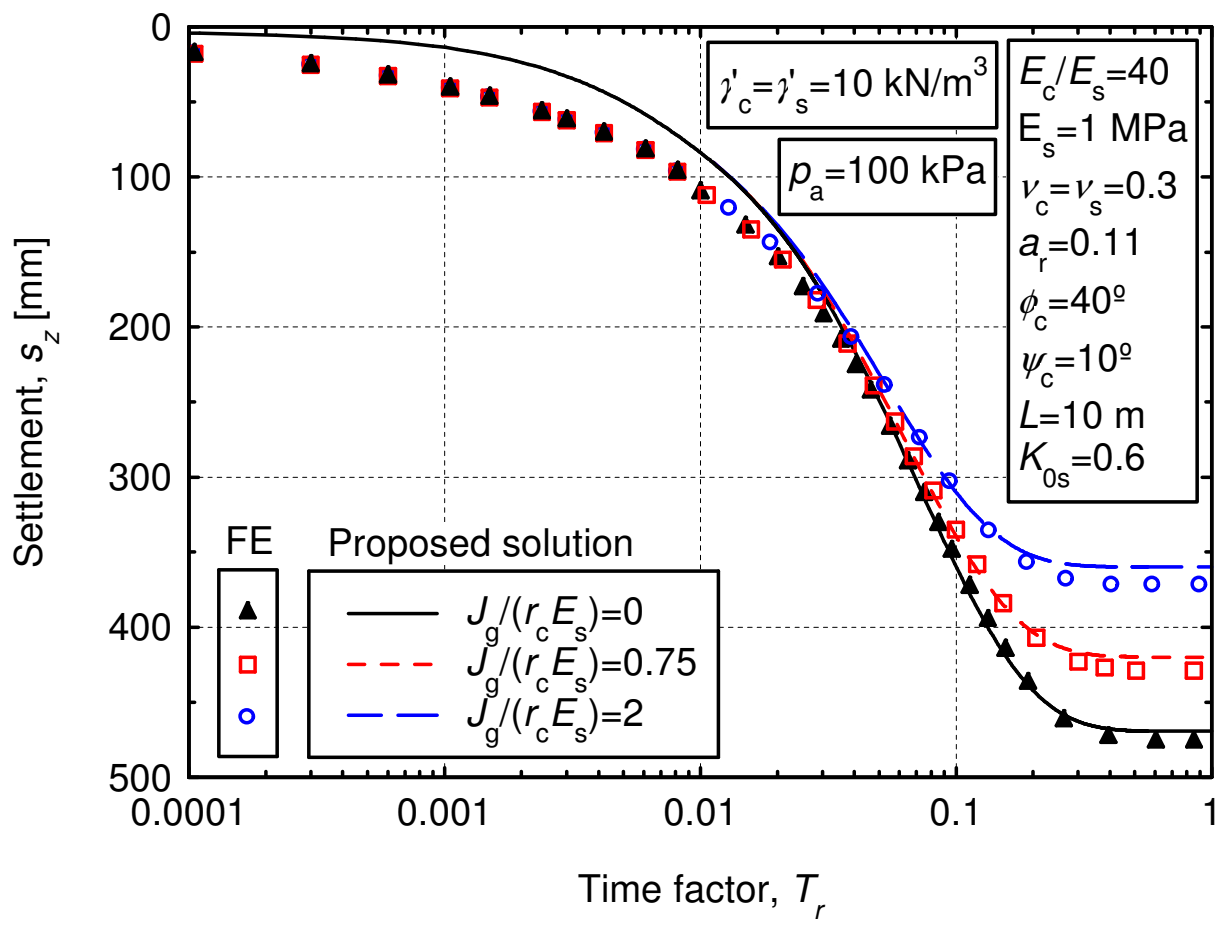

Figure 5. Time-settlement curves for common encasement stiffnesses. 


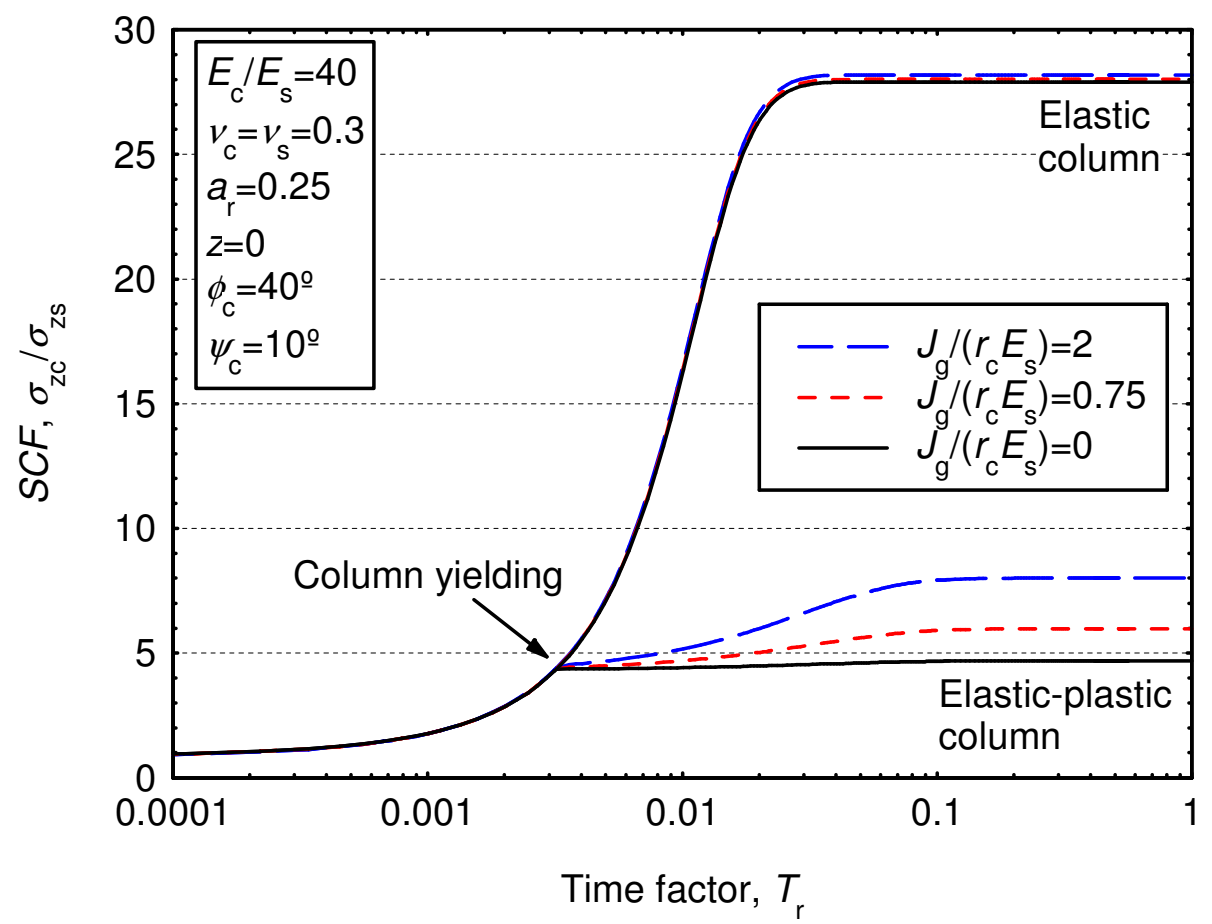

Figure 6. Stress concentration factor through time. Influence of the encasement stiffness. 


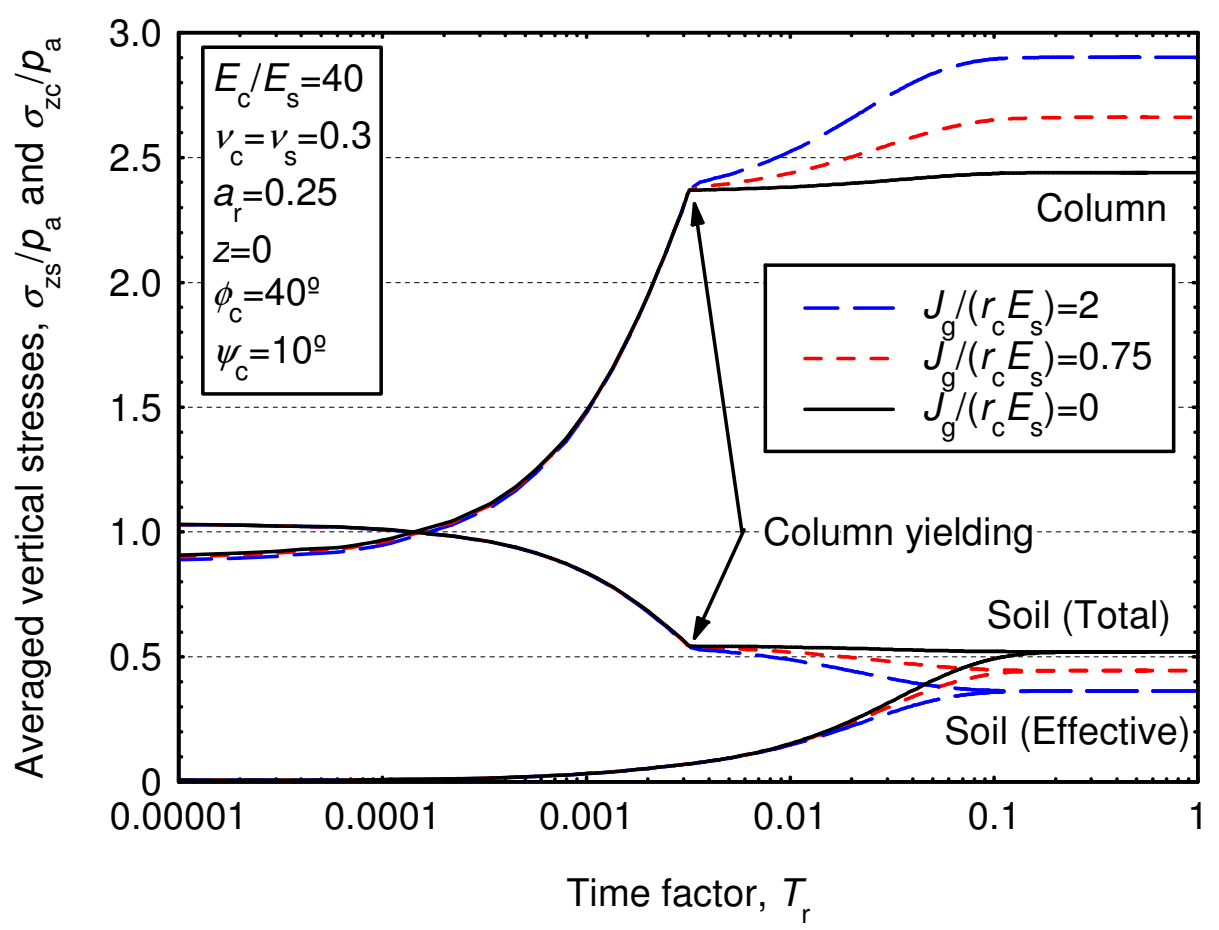

(a) Vertical stresses on the soil and the column

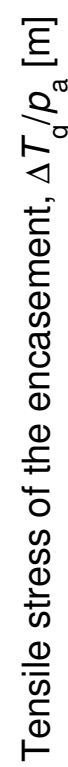

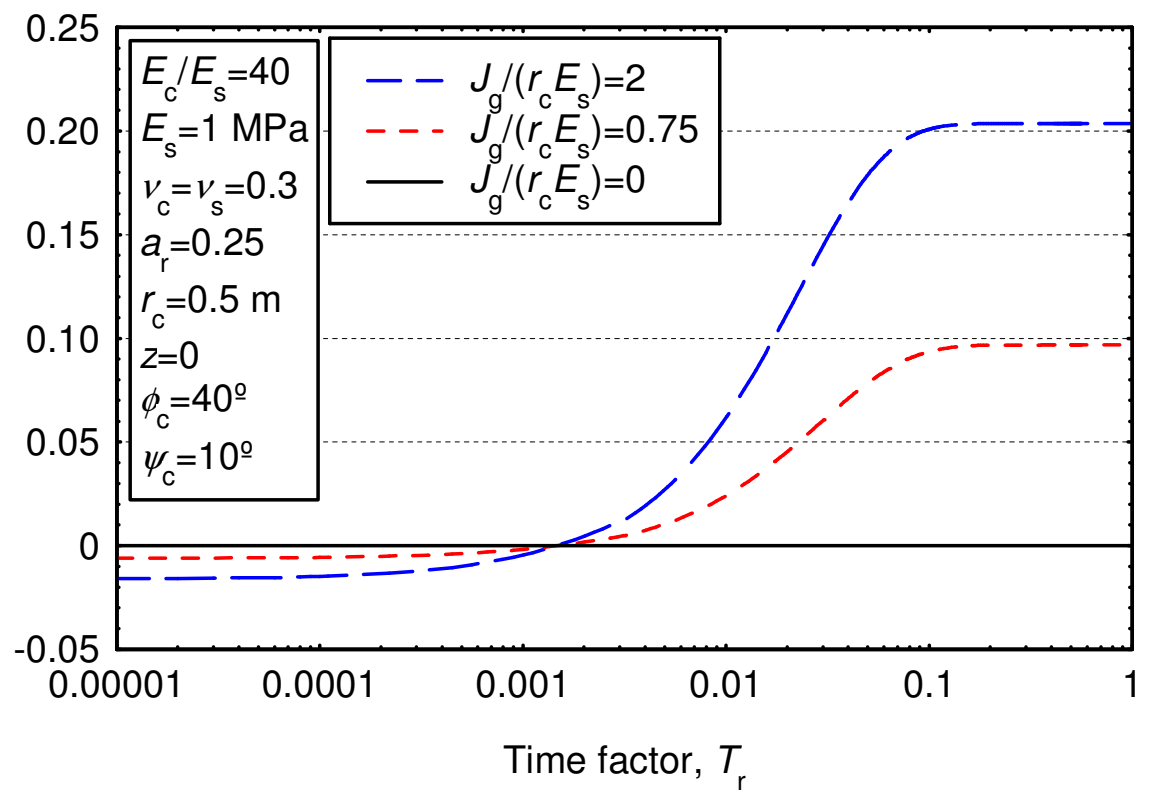

(b) Tensile stress of the encasement

Figure 7. Time-dependent stress transfer. 


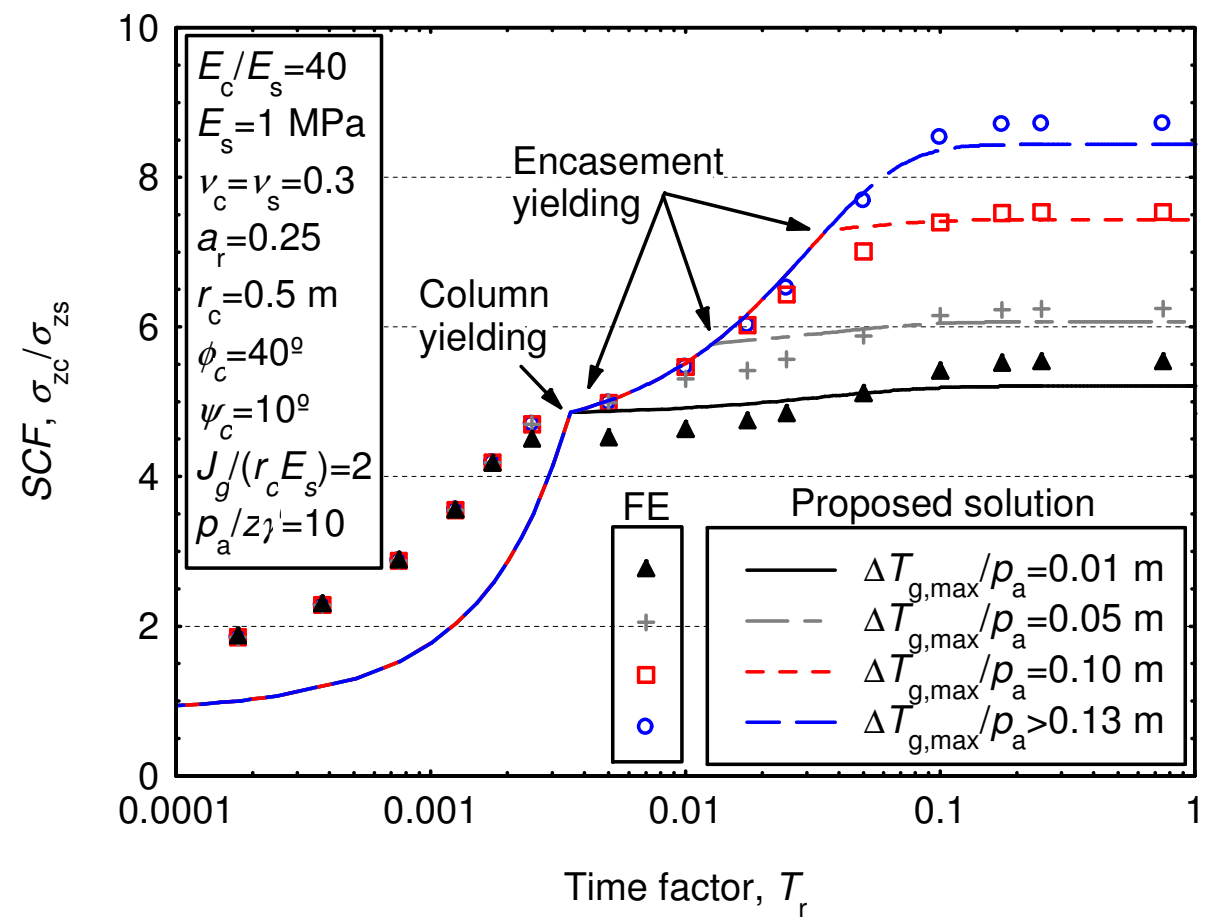

Figure 8. Stress concentration factor through time. Plastic column. Influence of the tensile strength of the encasement. 


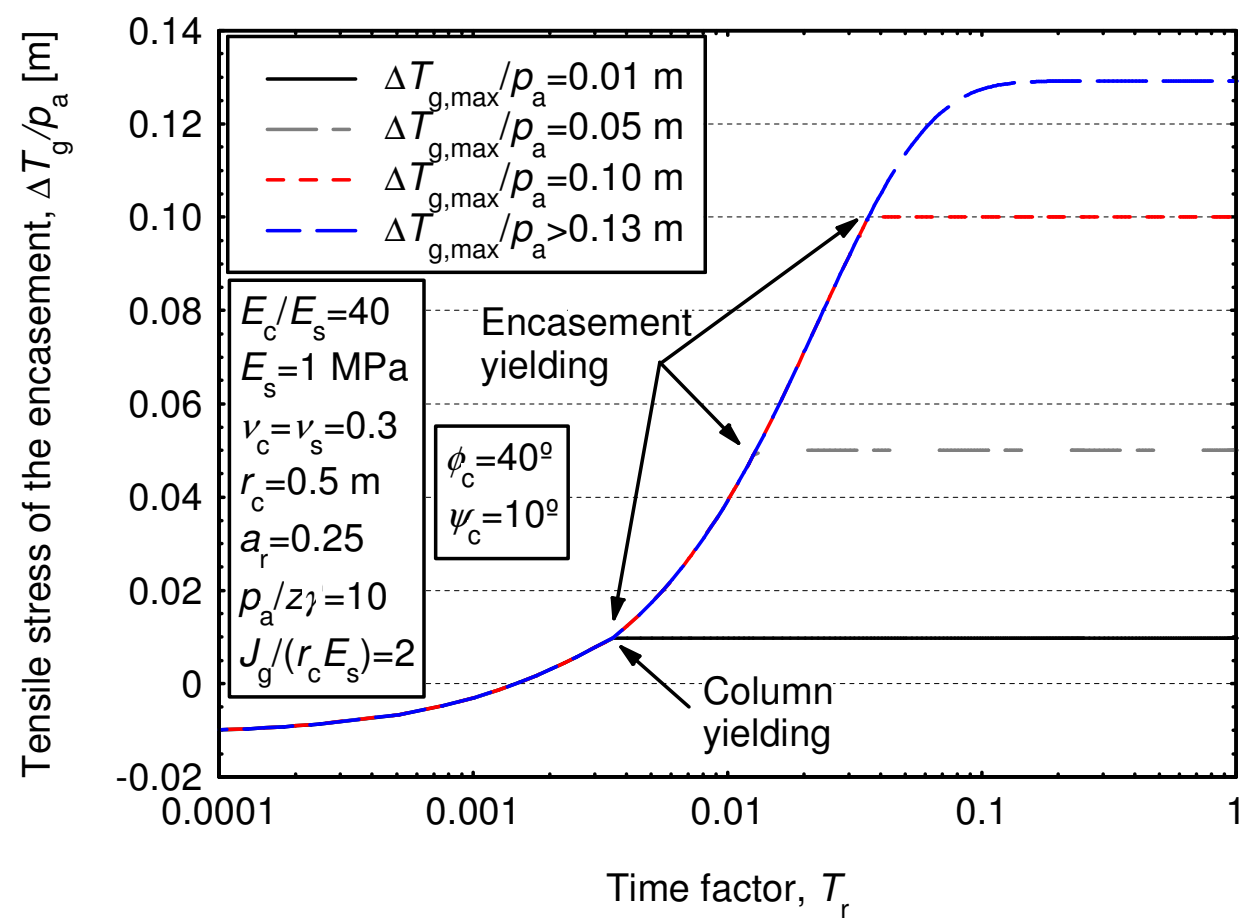

Figure 9. Tensile stress of the encasement. Plastic column. Influence of the tensile strength of the encasement. 

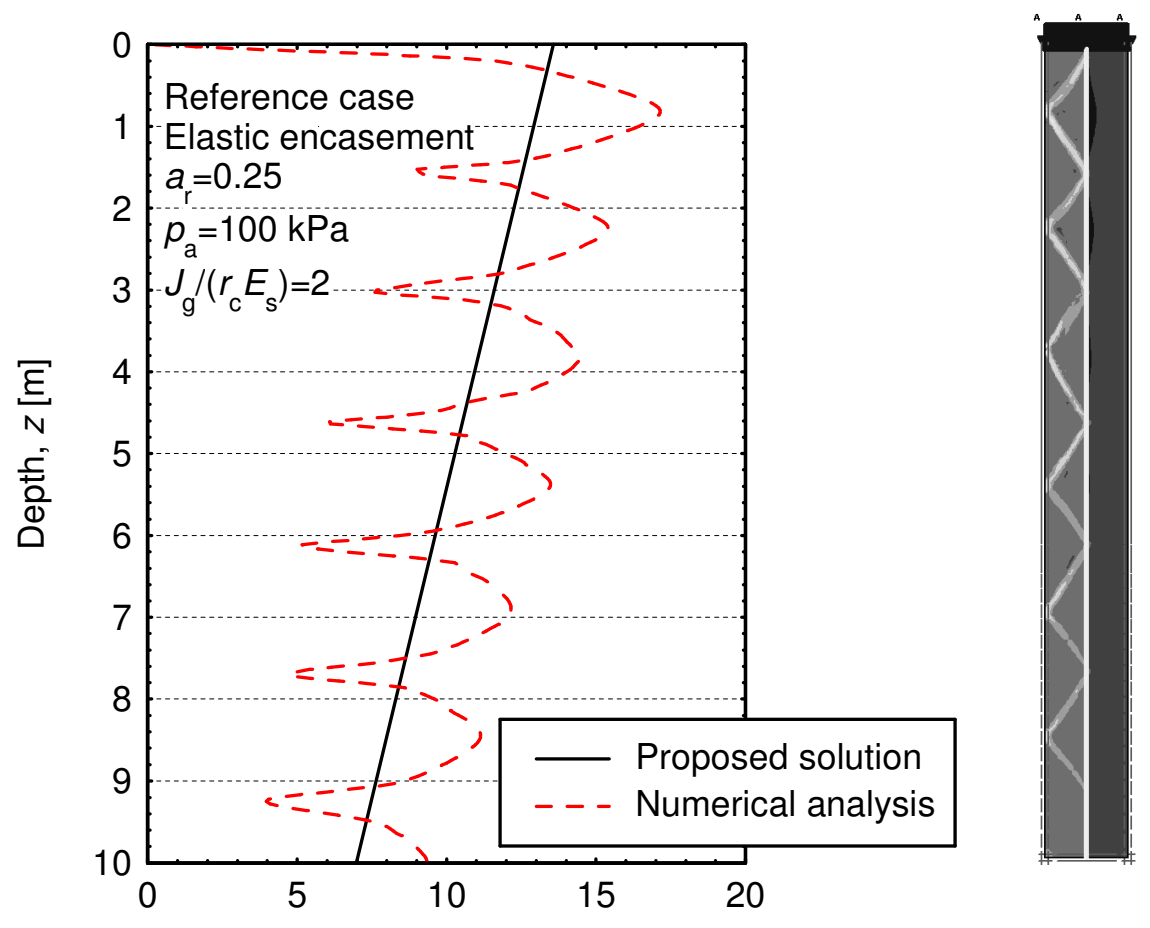

Tensile stress of encasement, $\Delta T_{g}[\mathrm{kN} / \mathrm{m}]$
(a) Comparison
(b) Shear bands

Figure 10. Comparison of the tensile stress of the encasement with numerical calculations. 


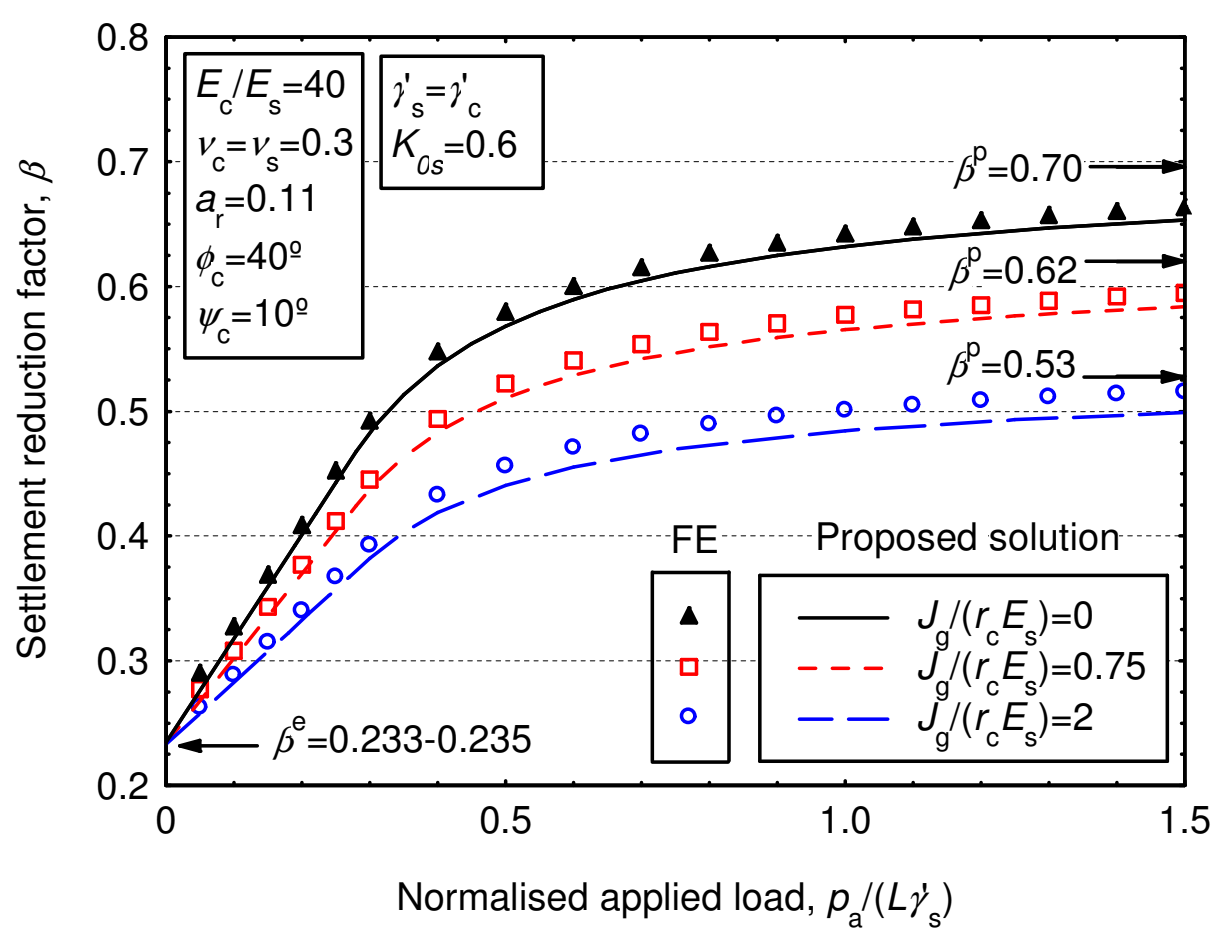

(a) Influence of the encasement stiffness

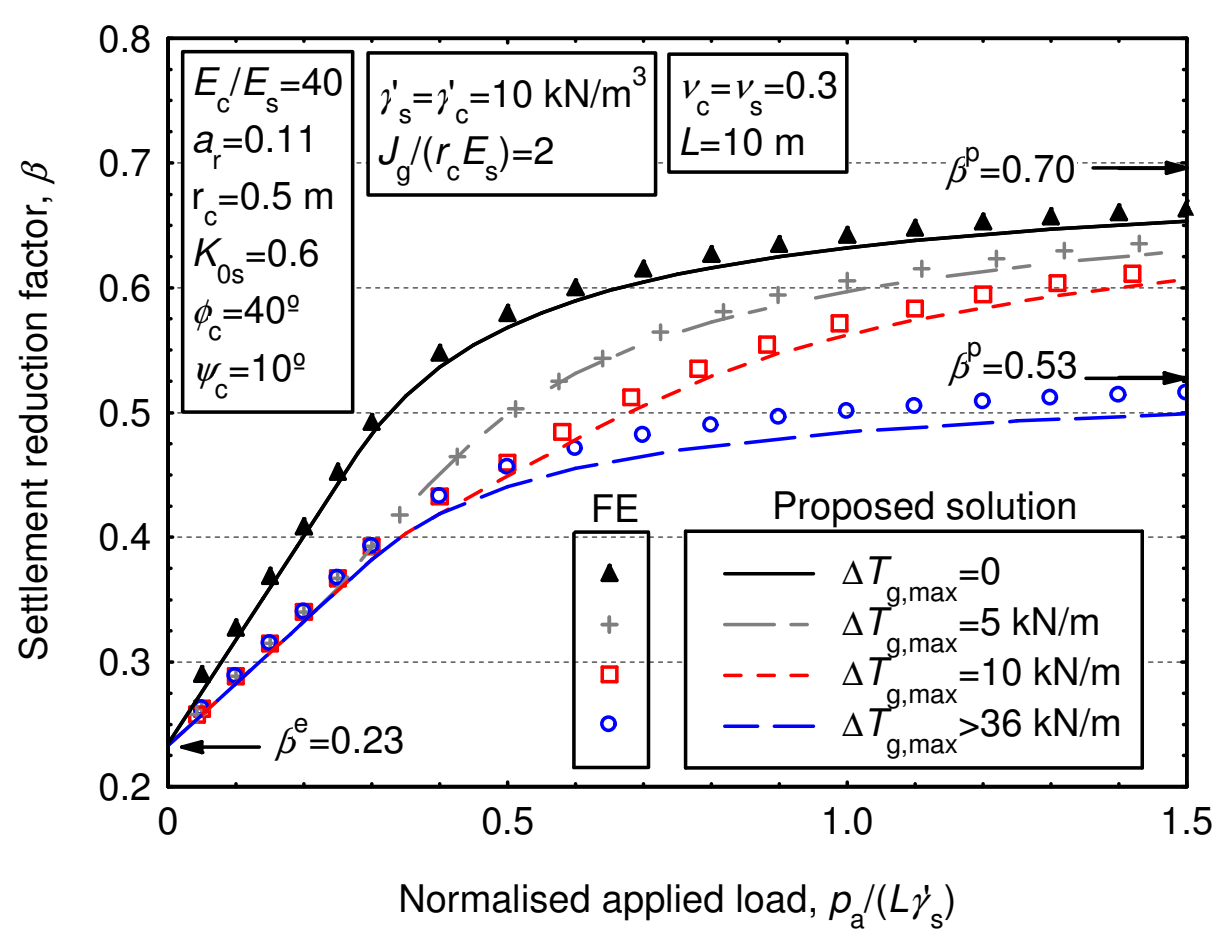

(b) Influence of the encasement tensile strength

Figure 11. Settlement reduction factor, $\beta$, with the applied load. 


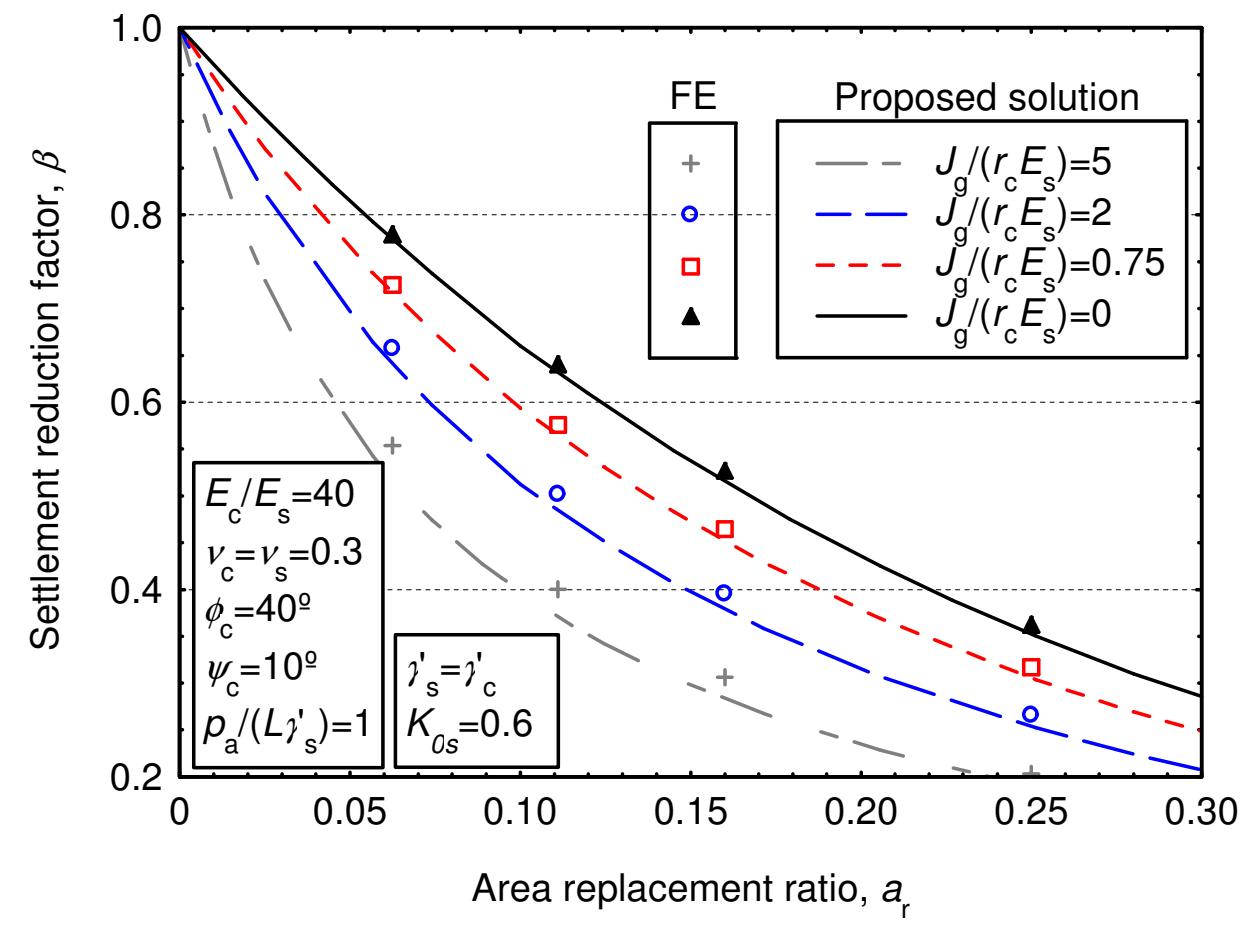

Figure 12. Settlement reduction factor, $\beta$. Influence of the encasement stiffness for different area replacement ratios. 


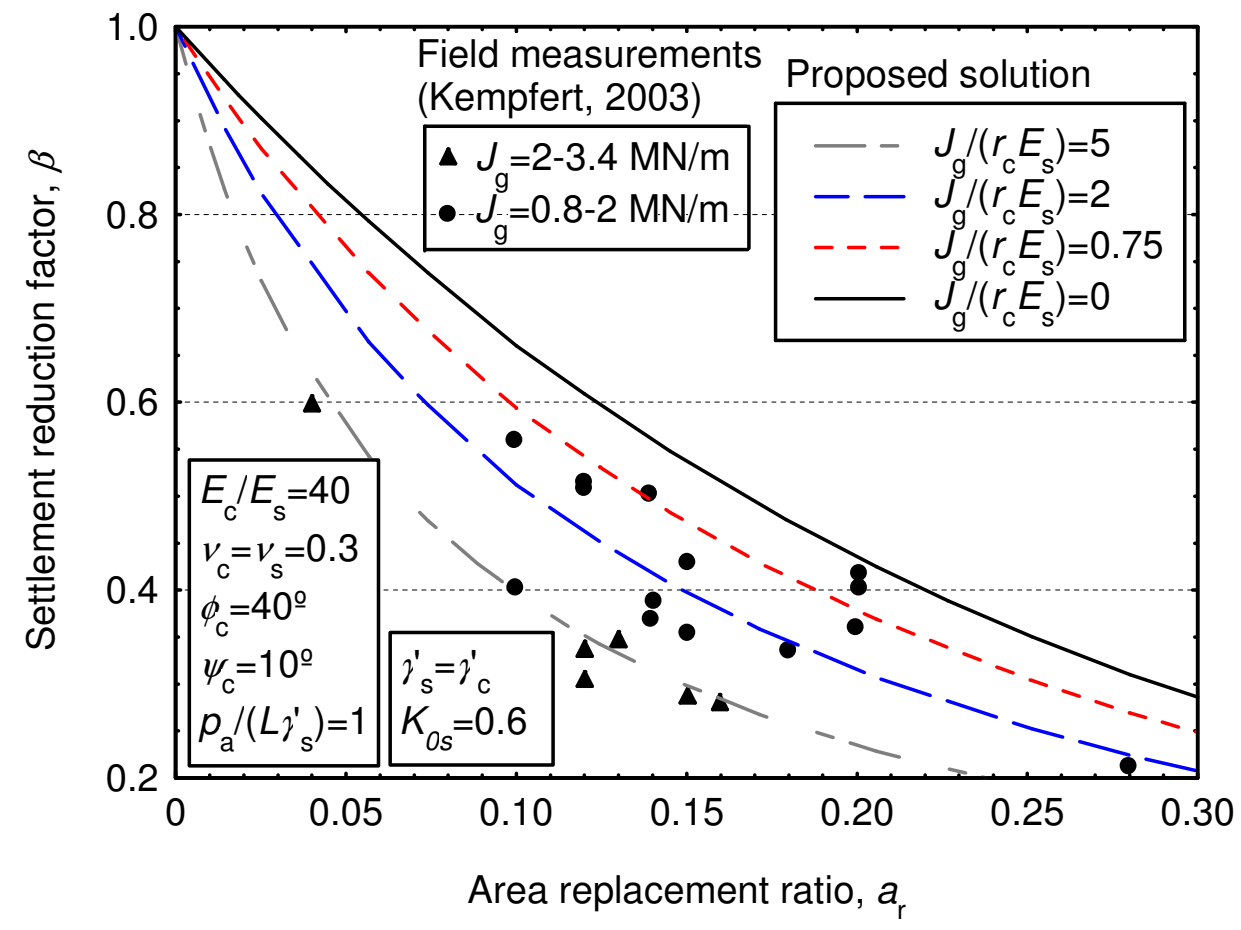

Figure 13. Settlement reduction factor, $\beta$. Comparison with field measurements. 


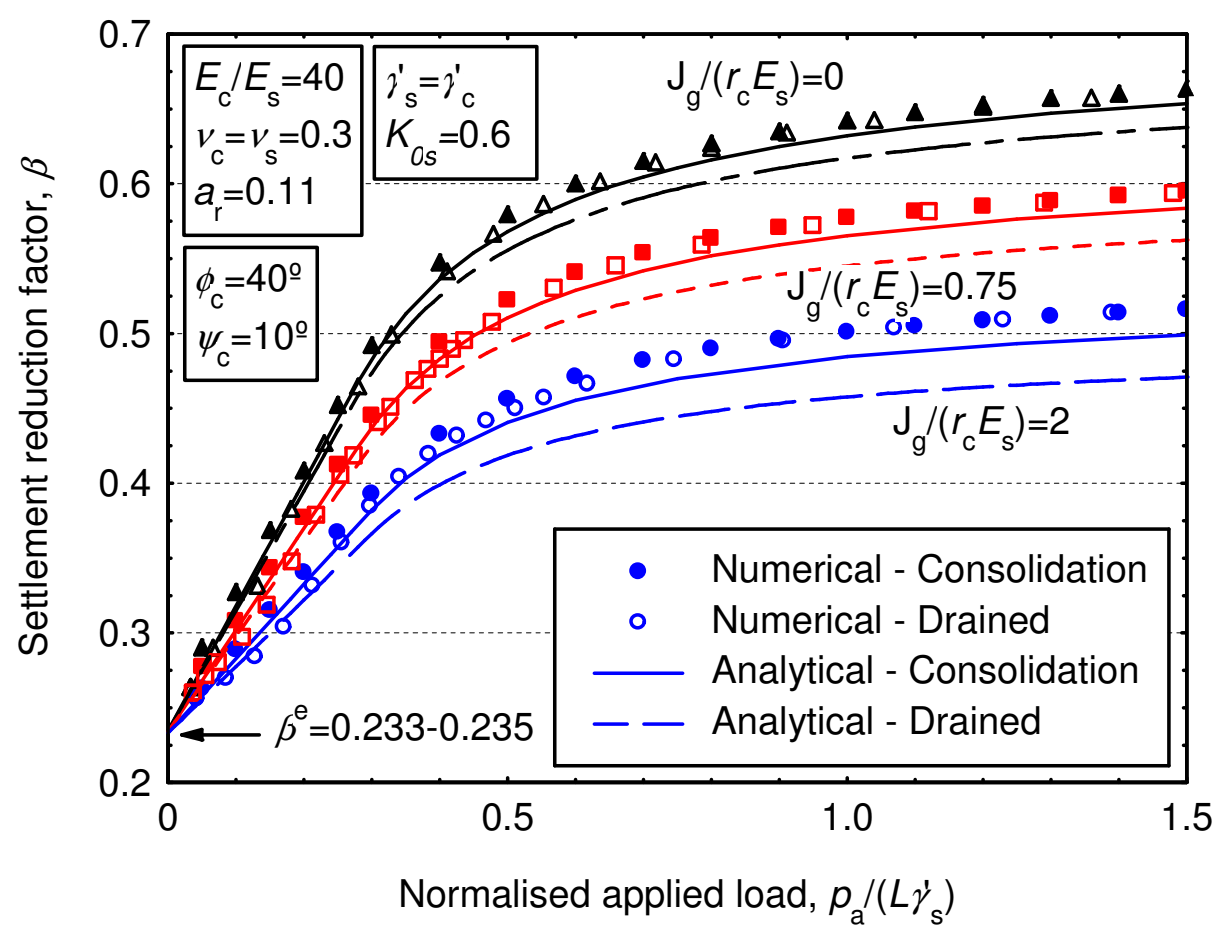

Figure 14. Comparison of drained and consolidation analyses. 
Table 1. Plastic increments of strains and stresses from the moment of column yielding for an increment of the applied load, $p_{a}^{p}$. Drained analysis.

\begin{tabular}{|c|c|c|}
\hline & Column (c) & Soil (s) \\
\hline Vertical strain, $\Delta \varepsilon_{z}^{p}$ & & $\frac{p_{a}^{p}}{E_{m l}^{p}}$ \\
\hline Radial displacement, $\Delta s_{r}$ & $r \frac{\Delta \varepsilon_{z}^{p}}{2 K_{\psi c}}$ & $r \frac{a_{r}}{1-a_{r}} \frac{1-\left(r / r_{l}\right)^{2}}{\left(r / r_{l}\right)^{2}} \frac{\Delta \varepsilon_{z}^{p}}{2 K_{\psi c}}$ \\
\hline Radial effective stress, $\Delta \sigma_{r}^{\prime}$ & $J \Delta \varepsilon_{z}^{p}$ & {$\left[\lambda_{s}+\frac{G_{s}\left(r_{c} / r\right)^{2}+a_{r}\left(G_{s}+\lambda_{s}\right)}{\left(1-a_{r}\right) K_{\psi c}}\right] \Delta \varepsilon_{z}^{p}$} \\
\hline Hoop effective stress, $\Delta \sigma_{\theta}^{\prime}$ & $J \Delta \varepsilon_{z}^{p}$ & {$\left[\lambda_{s}-\frac{G_{s}\left(r_{c} / r\right)^{2}-a_{r}\left(G_{s}+\lambda_{s}\right)}{\left(1-a_{r}\right) K_{\psi c}}\right] \Delta \varepsilon_{z}^{p}$} \\
\hline Vertical effective stress, $\Delta \sigma_{z}^{\prime}$ & $\frac{J \Delta \varepsilon_{z}^{p}}{K_{a c}}$ & {$\left[\lambda_{s}+2 G_{s}+\frac{a_{r} \lambda_{s}}{\left(1-a_{r}\right) K_{\psi c}}\right] \Delta \varepsilon_{z}^{p}$} \\
\hline Octahedral effective stress, $\Delta \sigma_{o c t}^{\prime}$ & $\frac{\left(2+1 / K_{a c}\right)}{3} J \Delta \varepsilon_{z}^{p}$ & $\left(\lambda_{s}+\frac{2}{3} G_{s}\right)\left[1+\frac{a_{r}}{\left(1-a_{r}\right) K_{\psi c}}\right] \Delta \varepsilon_{z}^{p}$ \\
\hline Volumetric strain, $\Delta \varepsilon_{v o l}$ & $\left(1-\frac{1}{K_{\psi c}}\right) \Delta \varepsilon_{z}^{p}$ & {$\left[1+\frac{a_{r}}{\left(1-a_{r}\right) K_{\psi c}}\right] \Delta \varepsilon_{z}^{p}$} \\
\hline
\end{tabular}

$$
\begin{gathered}
E_{m l}^{p}=\left(\lambda_{s}+2 G_{s}\right)\left(1-a_{r}\right)+\frac{a_{r} \lambda_{s}}{K_{\psi c}}+\frac{a_{r} J}{K_{a c}} \\
J=\lambda_{s}+\frac{G_{s}+a_{r}\left(G_{s}+\lambda_{s}\right)}{\left(1-a_{r}\right) K_{\psi c}}+\frac{J_{g}}{2 r_{c} K_{\psi c}}
\end{gathered}
$$

